\title{
Lipid Profile in Postmenopausal Diabetic Female.
}

\author{
Rabindra Simkhada, Sanjay Singh KC, Dharma Nath Yadav, Ravi Sahi
}

Department of Cardiology, Shahid Gangalal National Heart Centre, Kathmandu, Nepal.

Corresponding Author:

Rabindra Simkhada

Department of Cardiology, Shahid Gangalal National Heart Centre, Kathmandu, Nepal.

E-mail: rsimkhada2001@yahoo.com

ORCID ID: 0000-0002-3704-0175

Submitted Date: $25^{\text {th }}$ November 2020

Accepted Date: $10^{\text {th }}$ February 2021

Cite this article as: Simkhada R, KC S S, Yadav D N, et al. Lipid Profile in Postmenopausal Diabetic Female. Nepalese Heart Journal 2021; Vol 18 (1): 45-48

\section{Abstract}

Background and Aims: Postmenopausal diabetic female are at increased risk of cardiovascular disease. The objective of this study was to study their lipid profile and prevalence of dyslipidemia and assess relation of control of lipid components with various risk factors.

Methods: A cross sectional prospective study conducted at Shahid Gangalal National Heart Centre from $15^{\text {th }}$ July 2020 to $14^{\text {th }}$ October 2020 including 109 postmenopausal diabetic female. Detailed history along with clinical examination were conducted. Fasting lipid profile and other relevant investigations were obtained.

Results: Mean age of participants was $63.48 \pm 9.26$ years. Mean age of menopause was $48.59 \pm 1.88$ years. A total of 37 $(33.9 \%)$ were hypertensive, $17(15.6 \%)$ were smoker, 67 (61.5\%) were physically inactive. A total of $91(83.5 \%)$ were nonvegetarian. Thirty eight (34.9\%) had their blood sugar controlled with hemoglobin A1c of $<7 \%$. The mean total cholesterol and high density lipoprotein were $5.21 \pm 0.97 \mathrm{mmol} / \mathrm{l}$ and $1.02 \pm 0.13 \mathrm{mmol} / 1$. Similarly mean triglyceride and low density lipoprotein were $2.24 \pm 0.75 \mathrm{mmol} / 1$ and $3.04 \pm 0.12 \mathrm{mmol} / 1$. Dyslipidemia was present in $82.6 \%$. Significant correlation of control of blood sugar with total cholesterol control status $(\mathrm{R}=0.28, \mathrm{P}=0.01)$, low density lipoprotein control status $(\mathrm{R}=0.38$, $\mathrm{P}=0.01)$, high density lipoprotein control status $(\mathrm{R}=0.36, \mathrm{P}=0.04)$ and triglyceride control status $(\mathrm{R}=0.30, \mathrm{P}=0.04)$ were seen.

Conclusion: Dyslipidemia was common in post menopausal diabetic female. Blood sugar control status showed significant correlation with lipid profile parameters. A good sugar control and evaluation for lipid abnormalities is recommended in postmenopausal diabetic female.

Keywords: Diabetes; Lipid profile; Post menopause.

DOI: https://orcid.org/10.3126/njh.v18i1.36784

\section{Introduction}

Cardiovascular disease (CVD) is the most important cause of mortality and morbidity in female. ${ }^{1,2}$ Studies have shown postmenopausal females are at increased risk of CVD. ${ }^{3,4}$

Low estrogen and raised luteinizing and follicle stimulating hormone due to menopause causes significant unfavorable effect on lipid metabolism. Lipid friendly effect of estrogen like accelerated conversion of liver cholesterol to bile acid and expression of low density lipoprotein (LDL) receptor is lost. ${ }^{5,6}$ Studies in various settings have reported variable degree and pattern of dyslipidemia in postmenopausal female. ${ }^{6,7,8}$ Diabetes increases the risk of coronary heart disease by three to seven fold in women, whereas only two to three fold in men. ${ }^{1}$ Subtle changes in body composition during menopausal transition negatively influences glucose metabolism. ${ }^{9}$ Postmenopausal state was also significantly associated with the presence of dysglycemia. ${ }^{10}$ Postmenopausal diabetic female thus can

(a) Nepalese Heart Journal. Nepalese Heart Journal retain copyright and works is simultaneously licensed under Creative Commons Attribution License CC - By 4.0 that allows others to share the work with an acknowledge of the work's authorship and initial publication in this journal 
have added risk of CVD. Cardiovascular profile screening including lipids have been emphasized in postmenopausal women. ${ }^{11}$ Data focusing postmenopausal diabetic female on CVD is lacking in our part of world.

General objective of this study was to study lipid profile of postmenopausal diabetic female and the prevalence of dyslipidemia in our set up and specific objectives were to assess the relation of total cholesterol (TC), LDL, triglycerides (TG) and high density lipoprotein (HDL) control status with duration of menopause, blood sugar control status and duration of diabetes, physical activities, smoking, hypertension, dietary pattern and body mass index (BMI). This will help in more effective management of this high risk group.

\section{Methods}

This was a cross sectional prospective study conducted at Shahid Gangalal National Heart Centre (SGNHC). A total of 109 postmenopausal diabetic female presenting in outpatient department (OPD) or as an inpatient were enrolled from $15^{\text {th }}$ July 2020 to $14^{\text {th }}$ October 2020. The participants were enrolled on the basis of simple random sampling. Study was conducted after obtaining approval from institutional review Board (IRB) of SGNHC. Informed consent was taken from all the participants and only those participants who voluntarily opted to give consent were included.

The participants who had physiological menopause with amenorrhea for at least 1 year were enrolled. Women who had menopause due to hysterectomy or due to other than natural causes were excluded. Women on hormone replacement therapy and on lipid lowering medications were excluded. Diabetes mellitus (DM) was defined according to American Diabetic Association criteria with a fasting plasma glucose level $\geq 126 \mathrm{mg} / \mathrm{dl}(7.0 \mathrm{mmol} / \mathrm{l})$ or a 2 hour plasma glucose level $200 \mathrm{mg} / \mathrm{dl}(11.1 \mathrm{mmol} / \mathrm{l})$ or higher during a $75 \mathrm{mg}$ oral glucose tolerance test or a random plasma glucose of $200 \mathrm{mg} / \mathrm{dl}(11.1 \mathrm{mmol} / \mathrm{l})$ or more in a patient of classic symptom of hyperglycemia or hyperglycemic crisis or a hemoglobin A1c (HbA1c) level of $6.5 \%$ or higher. Both known diabetics and newly diagnosed diabetes were included. Among the enrolled participants whose HbAlc was $<7 \%$ was categorized as controlled diabetics. Relevant history was taken for variables like age, physical activity, smoking, and hypertension. At least 30 min of moderate physical activity a day was considered physically active. Dietary pattern whether nonvegetarian or vegetarian were noted. Patients were examined for height, weight and blood pressure (BP). A known hypertensive or whose BP was $\geq 140 / 90 \mathrm{mmHg}$ confirmed by two readings taken 5 minutes apart were categorized as hypertensive. Blood tests were done for fasting blood sugar, postprandial (PP) blood sugar, HbA1c and fasting lipid profile. Lipid profile were classified according to National Cholesterol Education Program Adult Treatment Panel III (NCEP ATPIII) and were categorized abnormal/uncontrolled if $\mathrm{TC} \geq 5.18 \mathrm{mmol} / 1(\geq 200 \mathrm{mg} / \mathrm{dl})$ or $\mathrm{TG} \geq 1.71 \mathrm{mmol} / 1(\geq 150 \mathrm{mg} / \mathrm{dl})$ or high density lipoprotein cholesterol (HDL) $<1.03 \mathrm{mmol} / 1 \quad(<40$ $\mathrm{mg} / \mathrm{dl})$ or LDL $\geq 2.59 \mathrm{mmol} / 1(\geq 100 \mathrm{mg} / \mathrm{dl})$ to see the prevalence of dyslipidemia. Those participants whose complete lipid parameters were not available were excluded.

Data were entered in the Statistical Package for the Social Sciences (SPSS) version 20 and were analyzed. For variables, frequency and percentage distribution and mean \pm standard deviation (SD) were calculated. Multiple linear regression analysis of TC, LDL, HDL and TG control with duration of menopause, blood sugar control status and duration of diabetes, physical activities, smoking, hypertension, dietary pattern and BMI was done. $\mathrm{P}$ values were calculated and values $<0.05$ were considered significant. The strength of correlation was measured with $\mathrm{R}$ value.

\section{Results}

The age of the participants ranged from 43 years to 90 years with mean age of $63.48 \pm 9.26$ years. Highest numbers of participants that is, $45(41.3 \%)$ were from age group $56-65$ years. It was followed by $33(30.3 \%)$ participants from age group 66-75 years and $17(15.6 \%)$ participants from age group $45-55$ years. There were $12(11 \%)$ participants with age more than 75 years and $2(1.8 \%)$ participants of less than 45 years. Age distribution of participants is shown in figure 1.

Figure 1: Age distribution of participants.

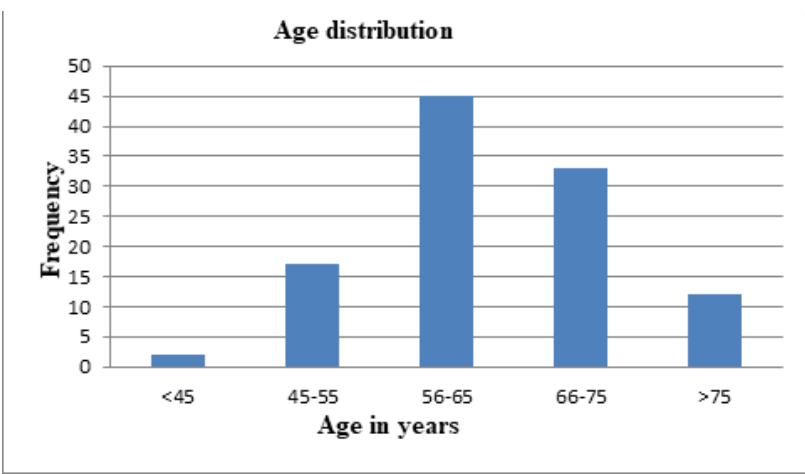

The age of onset of menopause ranged from 42 to 53 years and mean age of onset of menopause was $48.59 \pm 1.88$ years. The mean duration of menopause was $14.89 \pm 8.89$ years. A total of $10(9.8 \%)$ were newly diagnosed DM. The mean duration of DM was $9.09 \pm 6.52$ years.

A total of 37 (33.9\%) were hypertensive, 17 (15.6\%) were smoker, $67(61.5 \%)$ were physically inactive. A total of $91(83.5 \%)$ were non-vegetarian. The mean height, weight and BMI were $1.49 \pm 0.07$ $\mathrm{m}, 56.48 \pm 8.10 \mathrm{~kg}$ and $25.12 \pm 2.79 \mathrm{~kg} / \mathrm{m}^{2}$ respectively. The mean BP (Systolic BP/Diastolic BP) was 132.66 $\pm 2.79 / 83.15 \pm 9.12 \mathrm{mmHg}$. The mean sugar fasting, PP and $\mathrm{HbAlc}$ were $7.40 \pm 1.19 \mathrm{mmol} / \mathrm{l}$, $10.61 \pm 1.99 \mathrm{mmol} / 1$ and $7.25 \pm 1.3 \%$. Thirty-eight $(34.9 \%)$ had their blood sugar controlled with $\mathrm{HbAlc}$ of $<7 \%$. The demographic characteristics of the participants are shown in table 1.

Table 1: Demographic characteristics of participants.

\begin{tabular}{|ll|}
\hline Characteristics & No $(\%) /$ Mean \pm SD \\
\hline Hypertension & $37(33.9 \%)$ \\
\hline Smoker & $17(15.6 \%)$ \\
\hline Physically Inactive & $67(61.5 \%)$ \\
\hline Non-Vegetarian & $91(83.5 \%)$ \\
\hline Height $(\mathrm{m})$ & $1.49 \pm 0.07$ \\
\hline Weight $(\mathrm{kg})$ & $56.48 \pm 8.10$ \\
\hline BMI $\left(\mathrm{kg} / \mathrm{m}^{2}\right)$ & $25.12 \pm 2.79$ \\
\hline BP $(\mathrm{mmHg})$ & $132.66 \pm 2.79 / 83.15 \pm 9.12$ \\
\hline Sugar Fasting (mmol/1) & $7.40 \pm 1.19$ \\
\hline Sugar PP (mmol/l) & $10.61 \pm 1.99$ \\
\hline HbA1c $(\%)$ & $7.25 \pm 1.3$ \\
\hline
\end{tabular}


The mean TC and HDL cholesterol were $5.21 \pm 0.97 \mathrm{mmol} / 1$ and $1.02 \pm 0.13 \mathrm{mmol} / \mathrm{l}$. Mean TG and LDL were $2.24 \pm 0.75 \mathrm{mmol} / 1$ and $3.04 \pm 0.12 \mathrm{mmol} / 1$. Lipid profile of participants is shown in table 2 .

Table 2: Lipid profile of the enrolled participants.

\begin{tabular}{|ll|}
\hline Title & Value (Mean \pm SD) \\
\hline TC $(\mathrm{mmol} / \mathrm{l})$ & $5.21 \pm 0.97$ \\
\hline HDL $(\mathrm{mmol} / \mathrm{l})$ & $1.02 \pm 0.13$ \\
\hline TG $(\mathrm{mmol} / \mathrm{l})$ & $2.24 \pm 0.75$ \\
\hline LDL $(\mathrm{mmol} / \mathrm{l})$ & $3.04 \pm 0.12$ \\
\hline
\end{tabular}

A total of $90(82.6 \%)$ had dyslipidemia with at least one of the lipid component abnormality. Seventy nine $(72.5 \%)$ had high LDL, 77 (70.6\%) had hypertriglyceridemia, 73 (67\%) had low HDL and 68 $(62.4 \%)$ had hypercholesterolemia. The frequency of abnormal lipid components is shown in figure 2 .

Figure 2: Frequency of abnormal lipid components.

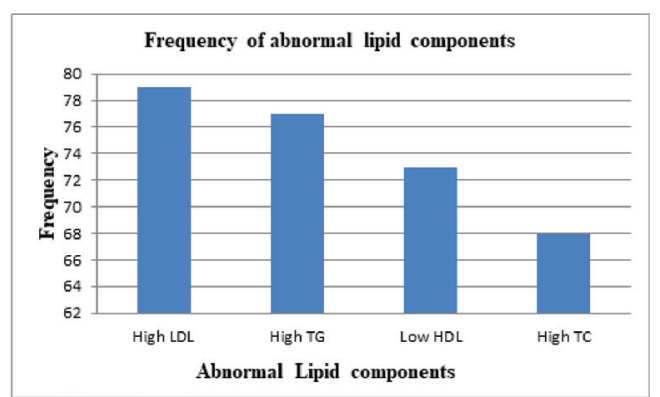

Multiple linear regression analysis showed significant correlation of control of blood sugar status with dependent variables TC control status $(\mathrm{R}=0.28, \mathrm{P}=0.01)$, LDL control status $(\mathrm{R}=0.38, \mathrm{P}=0.01), \mathrm{HDL}$ control status $(\mathrm{R}=0.36, \mathrm{P}=0.04)$ and $\mathrm{TG}$ control status $(\mathrm{R}=0.30$, $\mathrm{P}=0.04)$. Similarly BMI showed significant correlation with LDL control status $(\mathrm{R}=0.38, \mathrm{P}=0.03)$. Other variables showed no significant correlations with TC, LDL, HDL and TG control status. The variables and their $\mathrm{P}$ values are shown in table 3 .

Table 3: $\mathrm{P}$ values of lipid components' correlation with variables.

\begin{tabular}{|lllll|}
\hline Variables & TC & LDL & HDL & TG \\
\hline Duration of Menopause & 0.57 & 0.56 & 0.11 & 0.79 \\
\hline DM Duration & 0.97 & 0.35 & 0.98 & 0.71 \\
\hline Sugar Control & 0.01 & 0.01 & 0.04 & 0.04 \\
\hline Hypertension & 0.59 & 0.06 & 0.34 & 0.12 \\
\hline Smoking & 0.69 & 0.76 & 0.94 & 0.57 \\
\hline Physical Activities & 0.87 & 0.88 & 0.88 & 0.80 \\
\hline Dietary Pattern & 0.98 & 0.75 & 0.48 & 0.49 \\
\hline BMI & 0.93 & 0.03 & 0.87 & 0.24 \\
\hline
\end{tabular}

\section{Discussion}

In our study the mean age of participants was $63.48 \pm 9.26$ years The mean age of menopause was $48.59 \pm 1.88$ years. Rajbhandari and colleagues reported mean age of menopause 48.7 years. ${ }^{12}$ Shrestha and colleague had shown mean age of menopause at $48.02 \pm 2.12$ years. ${ }^{13}$ Ghimire and colleagues found median age of menopause at 47 years. ${ }^{14}$ Our findings were thus in consistence with published literatures.

We found $33.9 \%$ hypertensive, $15.6 \%$ smoker, and $61.5 \%$ physically inactive. Only $34.9 \%$ had blood sugar controlled with $\mathrm{HbA} 1 \mathrm{c}<7 \%$. Since diabetes is considered as coronary heart disease (CHD) equivalent, we recommend for control of conventional risk factors and blood sugar. In our study mean TC and HDL cholesterol were $5.21 \pm 0.97 \mathrm{mmol} / 1$ and $1.02 \pm 0.13 \mathrm{mmol} / \mathrm{l}$. Mean TG and LDL were $2.24 \pm 0.75 \mathrm{mmol} / 1$ and $3.04 \pm 0.12 \mathrm{mmol} / \mathrm{l}$. A total of $82.6 \%$ had dyslipidemia with at least one of the lipid parameter abnormality. In a study by Prajapati et al in India a total of $61.11 \%$ had total cholesterol $\geq 200 \mathrm{mg} / \mathrm{dl}, 66.67 \%$ had TG $\geq 150 \mathrm{mg} / \mathrm{dl}, 61.11 \%$ had LDL $\geq 130 \mathrm{mg} /$ $\mathrm{dl}$ and $50 \%$ had $\mathrm{HDL}<50 \mathrm{mg} / \mathrm{dl}$ in type 2 diabetic female. ${ }^{11}$ Baranwal et al had reported total cholesterol of $196.16 \pm 41.5 \mathrm{mg} / \mathrm{dl}$, HDL $33.5 \pm 5.4 \mathrm{mg} / \mathrm{dl}$, LDL $112.2 \pm 22.3 \mathrm{mg} / \mathrm{dl}$ and TG $172 \mathrm{mg} / \mathrm{dl}$ in the participants of uncontrolled blood sugar with $\mathrm{HbA1c} \geq 7 .{ }^{15}$ Ismail had shown TC of $198.49 \pm 54.79 \mathrm{mg} / \mathrm{dl}, \mathrm{HDL}$ of $43.93 \pm 14.98 \mathrm{mg} / \mathrm{dl}$, LDL $122.99 \pm 51.28 \mathrm{mg} / \mathrm{dl}$ and $\mathrm{TG}$ of $149.44 \pm 82.78 \mathrm{mg} / \mathrm{dl}$ in uncontrolled DM patients. ${ }^{16}$ Gomina and colleagues had reported the prevalence of dyslipidemia of $86.98 \%$ in postmenopausal female. ${ }^{7}$ Our findings of dyslipidemia in postmenopausal diabetic female was thus comparable with published literatures. We found significant correlation of control of blood sugar with all individual lipid profile components including TC, LDL, HDL and TG control. It was in consistence with findings of Azad et al who showed significant correlation of TC, HDL, LDL and TG with blood sugar. They found sugar control had strong impact on the serum lipid and dyslipidemia was frequently seen in those with poor sugar control. ${ }^{17}$

This study has few limitations. It was a single centre study with limited sample size. We considered only TC, HDL, LDL and TG. Analysis of other lipids and lipoprotein sub fractions like small dense LDL, large and buoyant LDL, small and large HDL would have been more informative. ${ }^{18}$

\section{Conclusion}

In this study, we found dyslipidemia common in postmenopausal diabetic female when guideline recommended standard cutoff limit was used. There was significant correlation of sugar control status with control status of all parameters of lipid profile. Since postmenopausal diabetic female are at increased risk of CVD, we recommend good blood sugar control and adequate evaluation and control of dyslipidemia in them.

\section{Source of funding: None \\ Conflict of interest: None}

\section{References}

1. Gulati M, Merz CN. Cardiovascular disease in women. In: Zipes DP, Libby P, Bonow RO, et al, editors. Braundwald's Heart disease.Vol 2.11th ed. New Delhi: ELSEVIER; 2019. p. 1767-1779.

2. Shaw LJ, Charney P, Wenger NK. Women and Ischemic heart disease: An evolving Saga. In: Fuster V, Harrington RA, Naraula J, et al, editors. Hurst the Heart. Volume 2.14th ed. New York: McGraw-Hill; 2017. p. 2414-2433. 
3. Tandon VR, Mahajan A, Sharma S, et al. Prevalence of cardiovascular risk factors in postmenopausal women: A rural study. J Midlife Health. 2010;1(1):26-29. https://doi.org/10.4103/0976-7800.66993

4. Newson L. Menopause and cardiovascular disease. Post Reproductive Health. 2018;24(1):44-49. https://doi.org/10.1177/2053369117749675

5. Das J, Sharma JD, Mazumdar S, et al. Dyslipidemia in Postmenopausal Women: A Case Control Study. Chittagram Maa-O-Shishu Hospital Medical college journal. 2013;12(2):7-12.

6. Pardhe BD, Ghimire S, Shakya J, et al. Elevated Cardiovascular Risks among Postmenopausal Women: A Community Based Case Control Study from Nepal. Biochem. Res. Int. 2017;2017:1-5. https://doi.org/10.1155/2017/3824903

7. Gomina M, Ele RN, Imoru RS, et al. Prevalence and factors associated with dyslipidemia among menopausal women in the city of Parakou (Benin). International Research Journal of Biochemistry and Bioinformatics.2017;7(1):12-18. http://dx.doi.org/10.14303/irjbb.2017.011

8. Sapkota AS, Sapkota A, Acharya K, et al. Study of metabolic syndrome in postmenopausal women. ACCLM. 2015;1(1):611. https://doi.org/10.3126/acclm.v1i1.12307

9. Chandrasekhar V. Diabetes and Menopause. Journal of Anesthesia \& Critical Care: Open Access. 2016;6(4):1-4. https://doi.org/10.15406/jaccoa.2016.06.00233

10. Heianza Y, Arase Y, Kodama S, et al. Effect of Postmenopausal Status and Age at Menopause on Type 2 Diabetes and Prediabetes in Japanese Individuals: Toranomon Hospital Health Management Center Study 17. Diabetes care. 2013;36:4007-4014.

https://doi.org/10.2337/dc13-1048
11. Prajapati B, Raval S, Patel J, et al. A study of clinical profile of cardiovascular manifestations in postmenopausal women. International archives of integrated medicine. 2018;5(4):100106

12. Rajbhandari S, Subedi RK, Dangal G, et al. Menopausal Health Status of Nepalese Women. J Nepal Med Assoc 2017;56(205):107-111. https://doi.org/10.31729/jnma.2907

13. Shrestha NS, Pandey A. A study of menopausal symptoms and its impact on lives of Nepalese perimenopausal and postmenopausal women. Journal of Kathmandu Medical College. 2017;6(1):4-8. https://doi.org/10.3126/jkmc.v6i1.18579

14. Ghimire N, Dhakal P, Norrish D, et al. Menopausal Health Status of Women of Kapilvastu District of Nepal. J Nepal Health Res Counc 2015;13(31):182-187.

15. Baranwal JK, Maskey R, Majhi S, et al. Association between level of HbAlc and lipid profile in T2DM patients attending diabetic OPD at BPKIHS. Health Renaissance 2015;13(3):1623. https://doi.org/10.3126/hren.v13i3.17923

16. Ismail KH. Lipid Profile of Controlled and Uncontrolled Diabetics in Erbil, Iraq. Iraqi J. Comm. Med. 2014;1:10-13.

17. Azad AH, Khan HR, Nasir GM, et al. Lipid Profile Abnormalities in Controlled and Uncontrolled Diabetic Patients: A Comparative Study. Ann. Pak. Inst. Med. Sci. 2017; 13(2):208-212.

18. Fonseca MH, Da Silva IT, Ferreira SR. Impact of menopause and diabetes on atherogenic lipid profile: is it worth to analyse lipoprotein subfractions to assess cardiovascular risk in women? Diabetol Metab Syndr. 2017; 9:22. https://doi.org/10.1186/s13098-017-0221-5 